\title{
Myocardial Distribution of Blood Flow in the Dog, Studied by the Labeled Microsphere
}

\author{
Part I. Method
}

\author{
Yasuro Sugishita, M.D., Shigekoto Kainara, M.D., Hisakazu \\ Yasuda, M.D., Masahiro Iro, M.D., Satoru Murao, M.D., \\ and Hideo Ueda, M.D.
}

\section{SUMMARY}

In 5 anesthetized dogs, "carbonized microsphere " labeled with Sr85 was injected into left atrium, and then the heart was excised and divided into 4 heart chambers and interventricular septum. Total and regional myocardial blood flow was calculated from the relative distribution of radioactivity, the weight of each myocardium samples and cardiac output, by the principle that the injected microspheres are distributed in the heart in proportion to the distribution of the regional myocardial blood flow. Total myocardial blood flow was $5.35 \pm 1.00 \%$ of the cardiac output, and the average myocardial flow per $100 \mathrm{Gm}$. of the myocardium was $76.3 \pm 15.5 \mathrm{ml} / \mathrm{min} . / 100 \mathrm{Gm}$. Right ventricle was supplied significantly less blood flow than left ventricle. The blood flow in the basal portion of right ventricle was less than that in the apical. There was no significant difference among the perfusion areas of left ventricle, but endocardial side of left ventricle was supplied with more flow than epicardial side. Interventricular septum had a similar pattern of flow distribution to left ventricular free wall. The total coronary sinus flow was collected during the injection of the microspheres using a cannula introduced into coronary sinus via right auricular appendage, and no significant coronary arteriovenous shunt was found.

\section{Additional Indexing Words :}

Radioactive microsphere Regional myocardial blood flow Right ventricle Left ventricle Interventricular septum Coronary arteriovenous shunt

7 HE blood flow supplied to the heart has generally been measured as a 1 whole, or as the left or the right heart flow. The nitrous oxide method, which collect the blood through the coronary sinus, is considered to measure mainly the left ventricular myocardial blood flow. Rb-86 method reveals

From the Second Department of Internal Medicine, Faculty of Medicine, University of Tokyo, Tokyo.

Received for publication March 31, 1970. 
the flow of the whole heart. Radioactive rare gas injection by the coronary artery catheterization reveals the left and the right heart blood flow separately. The development of the electromagnetic flowmeter has made it possible to measure the blood flow as the phasic flow through the anterior descending branch, the circumflex branch of the left coronary artery or the right coronary artery separately. Recently the ratio of myocardial blood flow in endocardial side to that in epicardial side of left ventricle has been obtained by Rb-86 clearance.

In 1965, Ueda et al. ${ }^{1}$ showed the unevenness of myocardial blood flow (MBF) among cardiac chambers, using I-131 macroaggregated albumin (MAA) particles. But the nonuniformity of the size of MAA particles limited the further applicability of this method.

In this study, in order to measure the myocardial distribution of blood flow among the various perfusion areas in the heart, the radioactive microsphere with uniform size was used. This radioactive microsphere method has advantage that it can reveal easily the true or effective MBF and coronary arteriovenous shunt flow.

\section{METHOD}

Five mongrel dogs were anesthetized with sodium pentobarbital, the chest was opened in the 4th left intercostal space and the heart was cradled in the open pericardium under artificial respiration. A thin polyvinyl catheter was inserted in the left atrium in order to inject the radioactive microspheres. Electromagnetic flowmeter transducer (Nihon-kohden Co.) was placed around the root of the aorta to measure the aortic blood flow. Another catheter was inserted into the femoral artery to measure the blood pressure.

Just after the measurement of the aortic blood flow and the blood pressure, about $0.1 \mathrm{ml}$. of the $1.0 \mathrm{Gm} . / 10 \mathrm{ml}$. saline solution of the microsphere* $(10 \mu \mathrm{Ci})$ was injected into the left atrium through the catheter. The microspheres thus injected are entrapped in the small vessels of the tissues or pass through arteriovenous shunt into distal circulation system. Following the injection the dog was sacrificed by the intravenous injection of potassium chloride, and the heart was excised. The visible epicardial fat and large vessels were removed. The atria were split into the left and the right. Both ventricular free walls were cut as close as possible to the interventricular septum. The left ventricular free wall was cut, as shown in Fig. 1, into the anterior (A) and the posterolateral (PL) portions, and each into the apical (1) and the basal (2) regions. And they were again divided into 2 layers; endocardial and epicardial sides. The interventricular septum was also divided into 2 layers; the left and the right sides. The right ventricular wall was divided into the apical and basal regions. Each heart sample was weighed, and was counted in a well-type scintillation counter.

\footnotetext{
* Sr-85 labeled microsphere with mean diameter of $15 \pm 5 \mu$. (IS.D.), 3 M Company, U.S.A.
} 


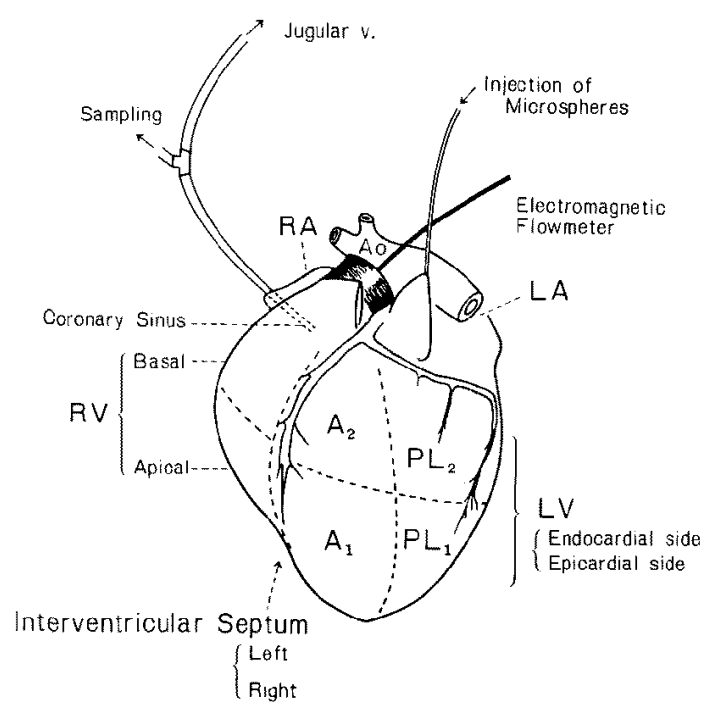

Fig. 1. Method for study.

LV: left ventricle, A: anterior, PL: posterolateral,

RV : right ventricle, LA: left atrium, RA: right atrium

The regional MBF was obtained by the fact that the injected microspheres are distributed in the heart in proportion to the distribution of the regional blood flow. The percentage of the total MBF to the aortic blood flow is given as:

$$
\frac{\text { Myocardial Blood Flow }}{\text { Aortic Blood Flow }}(\%)=\frac{\text { Total Heart Radioactivity }}{\text { Total Radioactivity Injected }}
$$

MBF is calculated as:

Total Myocardial Blood Flow (T.M.B.F.) (ml./min.)

$$
=\text { Aortic Blood Flow } \times \frac{\text { Total Hcart Radioactivity }}{\text { Injected Radioactivity }}
$$

Myocardial Blood Flow per $100 \mathrm{Gm}$. of Myocardium of the Whole Heart (ml./min./ $100 \mathrm{Gm}$. of myocardium)

$$
=\text { T.M.B.F. } \times \frac{100}{\text { Heart Weight }(\mathrm{Gm} .)}
$$

Regional Myocardial Blood Flow (ml./min./100 Gm. of myocardium)

$$
=\text { T.M.B.F. } \times \frac{\text { Rgional Radioactivity }}{\text { Total Heart Radioactivity }} \times \frac{100}{\text { Regional Weight (Gm.) }}
$$

Regional Myocardial Blood Flow is also expressed as the ratio to the myocardial blood flow per $100 \mathrm{Gm}$. of myocardium of the whole heart. In the formulae above, "myocardial blood flow" indicates the blood flow through the capillaries or the arterioles in the myocardium, smaller than $15 \mu$. in functional diameter. 
In some dogs, a polyethylene catheter with a balloon at the tip was inserted into the coronary sinus via right auricular appendage, to perfuse all the blood through it into the jugular vein and to collect blood sample at any time. When the radioactive microspheres were injected into left atrium, blood was taken through the catheter from the time of the injection till $3 \mathrm{~min}$. later, and the radioactivity which appeared in the blood was counted by scintillation counter. By this procedure coronary arteriovenous shunt flow can be known, which shows the shunt flow through the coronary sinus by the route of vessels larger than $15 \mu$. in functional diameter.

\section{RESULTS}

\section{1) Hemodynamic Data}

The mean and the standard deviation of hemodynamic data of 5 dogs at resting state are shown in Table $I$.

Table I. Hemodynamic Data

\begin{tabular}{l|c} 
Aortic Blood Flow & $993 \pm 86 \mathrm{ml} . / \mathrm{min}$. \\
Heart Rate & $171 \pm 18 \mathrm{beats} / \mathrm{min}$. \\
Mean Blood Pressure & $110 \pm 10 \mathrm{~mm} . \mathrm{Hg}$ \\
Total Myocardial Blood Flow & $52.6 \pm 7.2 \mathrm{ml} . / \mathrm{min}$. \\
Total Myocardial Blood Flow/Aortic Blood Flow & $5.35 \pm 1.00 \%$ \\
Myocardial Blood Flow per $100 \mathrm{Gm}$. of the Whole Heart & $76.3 \pm 15.5 \mathrm{ml} / \mathrm{min} . / 100 \mathrm{Gm}$.
\end{tabular}

Table II. Percentage of Regional MBF to the Total MBF

\begin{tabular}{l|c}
\hline \multicolumn{1}{c|}{ Chamber } & Percentage of the Total $(\%)$ \\
\hline Left Ventricle & $52.9 \pm 5.8$ \\
\{nterior Portion & $25.7 \pm 3.0$ \\
Posterolateral Portion & $27.1 \pm 4.8$ \\
Interventricular Septum & $21.1 \pm 5.3$ \\
Right Ventricle & $15.8 \pm 2.7$ \\
Left Atrium & $4.9 \pm 0.8$ \\
Right Atrium & $4.9 \pm 1.5$ \\
Coronary Arteriovenous Shunt & 0.0
\end{tabular}

\section{2) Distribution of $\mathrm{MBF}$}

The percentage of MBF of each cardiac chamber to the total are shown in Table II and Fig. 2. There was no significant coronary arteriovenous shunt through coronary sinus which could be detected by this method.

MBF per $100 \mathrm{Gm}$. of myocardium of cardiac chambers and of their perfusion areas are shown in Table III, and their ratios to MBF per $100 \mathrm{Gm}$. of myocardium of the total heart are shown in Table III and Fig. 3. Left ventricular free wall was supplied with as much blood flow as interventricular 


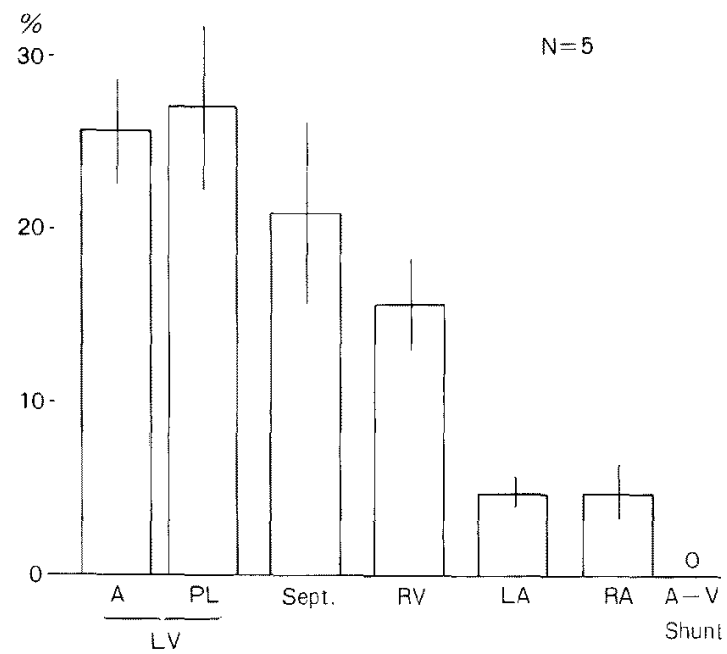

Fig. 2. Percentage of regional MBF to the total MBF. (Abbreviations are the same as in Fig. 1).

Table III. MBF in the Cardiac Chambers and Their Perfusion Areas

\begin{tabular}{l|l|c|c}
\hline \multicolumn{2}{c|}{ Region } & $\begin{array}{c}\text { MBF } \\
\text { (ml./min./100 Gm. }\end{array}$ & $\begin{array}{c}\text { Ratio of Regional MBF } \\
\text { to the Whole Heart MBF }\end{array}$ \\
\hline \multirow{3}{*}{$\begin{array}{c}\text { Left Ventricle } \\
\text { (free wall) }\end{array}$} & A-1 & $86.2 \pm 23.6$ & $1.12 \pm 0.12$ \\
& PL-1 & $80.6 \pm 22.6$ & $1.05 \pm 0.13$ \\
& PL-2 & $82.3 \pm 21.5$ & $1.07 \pm 0.06$ \\
& Total & $84.8 \pm 20.5$ & $1.11 \pm 0.09$ \\
\hline Interventricular Septum & $82.8 \pm 22.3$ & $1.09 \pm 0.06$ \\
\hline & Basal & $82.2 \pm 19.0$ & $1.08 \pm 0.06$ \\
\hline Right Ventricle & Apical & $59.6 \pm 15.7$ & $0.75 \pm 0.11$ \\
& Total & $70.3 \pm 16.8$ & $0.92 \pm 0.20$ \\
\hline Left Atrium & & $60.2 \pm 15.1$ & $0.79 \pm 0.13$ \\
\hline Right Atrium & & $62.3 \pm 10.8$ & $0.84 \pm 0.16$ \\
\hline
\end{tabular}

septum, but significantly more than right ventricle. There was no significant difference among MBF of the perfusion areas of left ventricle. MBF in the basal portion of right ventricle was less than that in the apical portion.

MBF per $100 \mathrm{Gm}$. of myocardium from the endocardial and epicardial sides of each perfusion areas of left ventricle and from the left and the right sides of the interventricular septum are shown in Table IV. Ratios of the each MBF per $100 \mathrm{Gm}$. of myocardium to the total heart blood flow are shown 


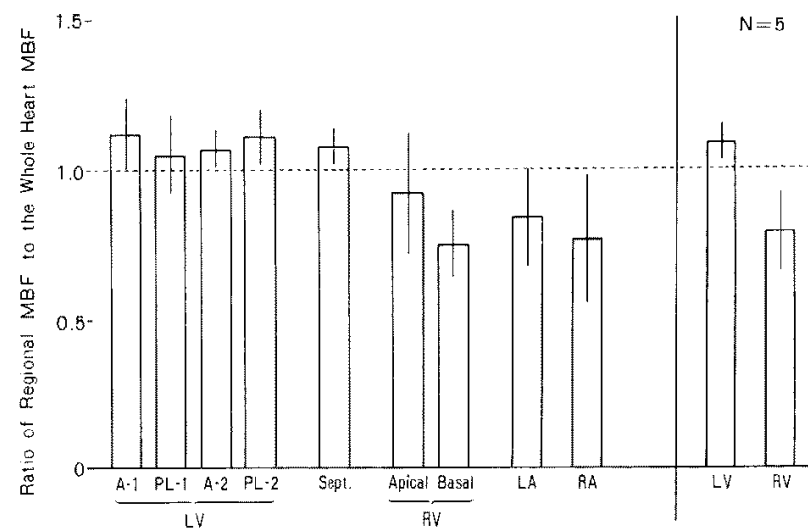

Fig. 3. MBF in the cardiac chambers and their perfusion areas. (Abbreviations are the same as in Fig. 1)

Table IV. MBF of Endocardial and Epicardial Sides of Left Ventricular Free Wall, and of Left and Right Sides of Interventricular Septum

\begin{tabular}{|c|c|c|c|c|}
\hline \multicolumn{3}{|c|}{ Region } & \multirow{2}{*}{$\begin{array}{c}\text { MBF } \\
(\mathrm{ml} . / \mathrm{min} . / 100 \mathrm{Gm} .) \\
100.9 \pm 45.9 \\
95.0 \pm 38.7 \\
93.4 \pm 34.0 \\
97.6 \pm 34.2\end{array}$} & \multirow{2}{*}{$\begin{array}{l}\text { Ratio of Regional MBF } \\
\text { to the Whole Heart MBF } \\
\qquad \begin{array}{c}1.25 \pm 0.26 \\
1.20 \pm 0.26 \\
1.18 \pm 0.18 \\
1.24 \pm 0.18\end{array}\end{array}$} \\
\hline \multirow{4}{*}{ 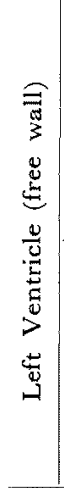 } & \multirow[t]{2}{*}{$\begin{array}{l}\text { Endocardial } \\
\text { Side }\end{array}$} & $\begin{array}{l}\text { A-1 } \\
\text { PL-1 } \\
\text { A-2 } \\
\text { PL-2 }\end{array}$ & & \\
\hline & & Total & $93.8 \pm 30.8$ & $1.22 \pm 0.17$ \\
\hline & \multirow[t]{2}{*}{$\begin{array}{l}\text { Epicardial } \\
\text { Side }\end{array}$} & $\begin{array}{l}\text { A-1 } \\
\text { PL-1 } \\
\text { A-2 } \\
\text { PL-2 }\end{array}$ & $\begin{array}{l}79.9 \pm 19.2 \\
74.4 \pm 23.1 \\
75.2 \pm 21.2 \\
76.9 \pm 21.8\end{array}$ & $\begin{array}{l}1.03 \pm 0.15 \\
0.93 \pm 0.17 \\
0.95 \pm 0.11 \\
0.97 \pm 0.13\end{array}$ \\
\hline & & Total & $75.2 \pm 17.9$ & $0.98 \pm 0.09$ \\
\hline \multirow{2}{*}{ 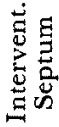 } & \multicolumn{2}{|l|}{ Left Side } & $101.1 \pm 14.7$ & $1.27 \pm 0.32$ \\
\hline & \multicolumn{2}{|l|}{ Right Side } & $73.8 \pm 16.4$ & $0.96 \pm 0.06$ \\
\hline
\end{tabular}

in Table IV and Fig. 4. Table $V$ shows the ratios of the endocardial MBF to the epicardial MBF of left ventricular free wall, and of the left to the right of interventricular septum. The endocardial side of left ventricle was supplied with more blood flow than the epicardial side, but there was no significant difference among their perfusion areas. The relation between the left and the right sides of interventricular septum was similar to that between the endocardial and epicardial sides of left ventricular free wall. 


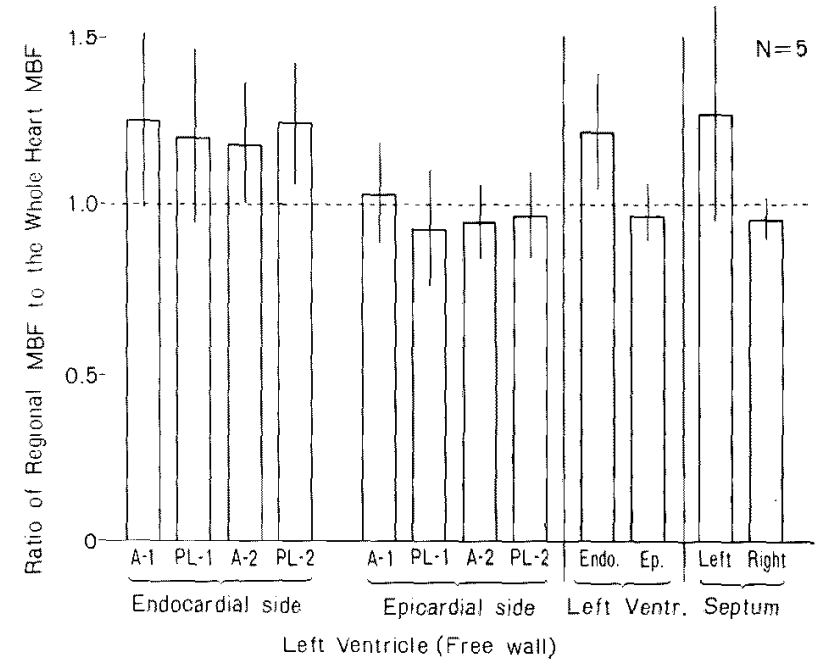

Fig. 4. MBE of endocardial and epicardial sides of left ventricular free wall, and of left and right sides of interventricular septum.

Table V. Endocardial to Epicardial Ratios of MBF at Left Ventricle and Left to Right Ratio at Interventricular Septum

\begin{tabular}{c|c|c}
\hline \multicolumn{2}{c|}{ Region } & ED/EP \\
\hline & A-1 & $1.25 \pm 0.25$ \\
Left Ventricle & PL-1 & $1.35 \pm 0.46$ \\
(free wall) & A-2 & $1.18 \pm 0.24$ \\
& PL-2 & $1.29 \pm 0.23$ \\
\hline Interventricular Septum (Left/Right) & $1.26 \pm 0.28$ \\
\hline
\end{tabular}

Discussion

In general, "coronary blood flow" is composed of 2 kinds of flow: first, "myocardial blood flow", the true or effective MBF, which is the flow through capillary level, and second," coronary arteriovenous shunt flow" which is not utilized for the metabolism of the myocardium. The microsphere method, which was applied in this study, can reveal these kinds of flow separately. This method can demonstrate not only the regional MBF expressed in $\mathrm{ml} . / \mathrm{min} . / 100 \mathrm{Gm}$. of myocardium but also its distribution throughout the whole heart. The microsphere method has also several other advantages. The method can be applied both in the open-chest state and in the closed chest, and both at anesthetized and unanesthetized conditions if a tube in left 
atrium and electromagnetic flowmeter transducer has previously been placed. As it is not necessary to take heart samples immediately after the injection, the change of MBF under different conditions can be measured in one animal, if the microspheres labeled with different kinds of radioactive nuclide are used as appeared in Part II of this paper. This method is not influenced by the metabolic processes of the heart, because the spheres are inert substance. The specific gravity of the sphere is about 1.3 , which is almost similar to that of red blood cells. It is also indispensable condition for such study. A steady state is needed only for a relatively short time, during which injection is performed. The disadvantages to this method are that the animal has to be sacrificed and so that it can not be applied for the clinical use. It could be supposed that the distribution of the microspheres of different size show the distribution of the blood flow through the vessels of different size. Recently it has been pointed out that the ratio of the endocardial blood flow to the epicardial blood flow of left ventricle measured by the microspheres of $50 \mu$. in diameter is larger than that by the microsphere of $15 \mu .{ }^{2), 3)}$ but Fortuin, Kaihara et al. considered that this could be explained by Fulton's theory of reservoir function of subendocardial plexus. ${ }^{2)}$ We have taken the $15 \mu$. spheres for use, because the $15 \mu$. spheres would behave as red blood cells in the vessels rather than $50 \mu$. spheres. Therefore, it would show the values closer to the true MBF than the larger spheres and would also be useful for the detection of coronary arteriovenous shunt. The smaller spheres would be also less influenced by the axial stream phenomenon in the arteries.

$\mathrm{Rb}-86$ has been used for the study of the myocardial distribution of blood flow, especially that between endocardial and epicardial layers of left ventricle.4)-6) The Rb clearance depends not only on MBF but also on extraction ratio of $\mathrm{Rb}$ between blood and tissue, which is usually assumed as constant. However, as $\mathrm{Rb}$ shifts between myocardial cells and tissue fluid just as potassium, the extraction ratio may be influenced by various metabolic states. Na$\mathrm{I}-131^{7)}$ and $\mathrm{Xe}-133$ or $\mathrm{Kr}-85^{8)}$ has also been used for the study by their local injection. They can exhibit only the regional MBF of the injected portion, not the distribution throughout the whole heart, and the results by these methods may be influenced by some factors as the injected volume, local edema and hemorrhage caused by the injection.

The ratio of total MBF to aortic blood flow calculated from this method was $5.35 \pm 1.00 \%$, which can be thought to be valid compared to the previous investigations. MBF per $100 \mathrm{Gm}$. of myocardium of the whole heart or of the left ventricle is comparable to the results of the other studies.

It is generally believed that MBF per weight of left ventricle is more than that of the right.2),55,6) This can be explained by the difference of their pres- 
sure loads. In this paper, left ventricle is supplied with MBF of $83.8 \mathrm{ml} . / \mathrm{min} . /$ $100 \mathrm{Gm}$. and right ventricle, $60.2 \mathrm{ml} . / \mathrm{min} . / 100 \mathrm{Gm}$. As the weight of myocardium of left ventricle was $34.80 \mathrm{Gm}$. on an average, and that of right ventricle $14.63 \mathrm{Gm}$. on an average, the ratio of total MBF of left ventricle to that of right was $3.30: 1$. Supposing the mean pulmonary artery pressure and mean aortic pressure $20 \mathrm{~mm} . \mathrm{Hg}$ and $90 \mathrm{~mm} . \mathrm{Hg}$ respectively and both ventricular volumes same, the ratio of work of the ventricles is $4.50: 1$. So it is reasonable that MBF per weight of left ventricle is more than that of right ventricle.

In right ventricle, the apical blood flow is more than the basal. This has been found by Chansky, ${ }^{5}$ ) too. Its mechanism is not clear, but it might be due to the difference of the contractile function of the 2 portions.

It has generally been shown that MBF in the endocardial side of left ventricle is larger than that in the epicardial side, ${ }^{6,9)}$ as in our study, except the contrary result obtained by NaI-131 clearance method." The larger flow in the endocardial side can be explained by Fulton's theory. Myer and Honig ${ }^{10}$ have also demonstrated a vascularity gradient increasing from epicardium to endocardium in the heart of dogs, and have calculated that this is primarily a difference in capillarity. Moir ${ }^{11}$ suggested some contribution of $\mathrm{Rb}$ uptake directly from the ventricular cavity to the higher clearance in the endocardial side.

Interventricular septum has a similar pattern of distribution of MBF to left ventricular free wall. This might be explained by the assumption that the functional structure of interventricular septum is nearly similar to that of left ventricular free wall, considering the fact that ventricular septum is concaved to the right and is, from the anatomical view, rather a part of left ventricle and that right ventricle is attached to left ventricle.

In left ventricle, there was no significant difference among MBF of perfusion areas, that is, in normal intact dogs blood flow is distributed homogeneously throughout left ventricle. This might partly be related to the fact that normal left ventricle performs an almost uniform contraction.

\section{REFERENCES}

1. Ueda, H., Kaihara, S., Ueda, K., Sugishita, Y., Sasaki, Y., and Iio, M.: Jap. Heart J. 6: $534,1965$.

2. Fortuin, N. J., Becker, L., Kaihara, S., and Pitt, B.: J. Clin. Invest. 48: 25a, 1969.

3. Demnach, R. J., Hoffman, J. I. E., Noble, M. I. M., Saunders, K. B., Henson, J. R., and Subijanto, S.: Circulat. Res. 25: 581, 1969.

4. Love, W. D. and Burch, G. E.: J. Clin. Invest. 36: 479, 1957.

5. Chansky, M. and Levy, M. N.: Circulat. Res. 11: 414, 1962.

6. Love, W. D., Munford, R. S., and Abraham, R. E.: I. Lab. Clin. Med. 66: 423, 1965. 
7. Kirk, E. S, and Honig, C. R.: Am. J. Physiol. 207: 661, 1964.

8. Sullivan, J. M., Taylor, W. J., Elliott, W., and Gorlin, R.: J. Clin. Invest. 46: 1402, 1967.

9. Love, W. D. and Tyler, H. D.: Am. J. Physiol. 208: 1211, 1965.

10. Myer, W. W. and Honig, C. R.: Am. J. Physiol. 207: 653, 1964.

11. Moir, T. W. and DeBra, D. W. Z.: Circulat. Res. 21 : 65, 1067. 